\title{
Determinação das propriedades físicas e mecânicas do gesso reciclado proveniente de chapas de gesso acartonado
}

\section{(Determination of physical and mechanical properties of recycled gypsum from the plasterboard sheets)}

\author{
A. Erbs, A. Nagalli, V. Mymrine, K. Q. Carvalho \\ Departamento Acadêmico de Construção Civil, Universidade Tecnológica Federal do Paraná, Campus Curitiba, \\ Sede Ecoville, R. Deputado Heitor de Alencar Furtado 5000, Curitiba, PR 81280-340 \\ nagalli@utfpr.edu.br
}

\begin{abstract}
Resumo
A busca pela viabilidade técnica e econômica da reciclagem de resíduos na cadeia produtiva da construção civil vem atender às novas necessidades do setor de promover crescimento econômico integrado às necessidades sociais e ambientais. $\mathrm{O}$ crescente aumento do consumo das chapas de gesso acartonado carrega consigo o problema da geração dos resíduos de gesso, onde a falta de pesquisa e o descarte incorreto acaba destinando o resíduo gerado, na maioria das vezes, para aterros ou bota-foras irregulares, sem controle ou estimativa de volume. No presente trabalho, por meio da adoção de um processo de reciclagem composto das etapas de moagem e calcinação do resíduo das chapas de gesso acartonado, determinaram-se as propriedades físicas e mecânicas do gesso reciclado proveniente das chapas de gesso acartonado. A análise dos resultados mostrou a viabilidade da reciclagem, pois após a reidratação foi possível moldar corpos de prova, demonstrando que é possível reciclar um produto que hoje é descartado.
\end{abstract}

Palavras-chave: reciclagem, gesso, chapa, acartonado.

Abstract

The search for technical and economic feasibility of waste recycling in the production chain of construction meets the new requirements of the sector to promote an integrated economic growth to social and environmental needs. The increasing consumption of plasterboard sheets brings along the problem of generation of gypsum waste, where the lack of research and incorrect disposal can result in the discharge of generated waste to landfills or irregular dumps, in most cases, without control or estimate of volume. In this work, using a recycling process comprised of grinding and calcining the residue of plasterboard sheets, the physical and mechanical properties of recycled gypsum from the drywall sheets were determined. The results showed the feasibility of recycling, because after rehydration it was possible to mold solid specimens using only the gypsum waste, demonstrating that it is possible to recycle a product that today is merely discarded in the environment.

Keywords: recycling, plaster, plasterboard sheets, gypsum.

\section{INTRODUÇÃO}

Drywall é um sistema para forro ou parede constituído por placas de gesso pré-fabricadas, parafusadas em uma estrutura metálica leve de aço galvanizado, sobre as quais são fixadas as placas de gesso, em uma ou mais camadas, gerando uma superfície apta a receber o acabamento final [1]. A composição típica do gesso acartonado é complexa. A parcela predominante é de gesso natural hidratado (gipsita), papel, fibras de vidro, vermiculita, argilas, amido, potassa cáustica $(\mathrm{KOH})$, agentes espumantes e dispersantes [2].

As perdas na construção do drywall apresentam-se elevadas devido às atividades de corte da chapa. Estimase que entre 10 a $12 \%$ do gesso acartonado é transformado em resíduos durante a instalação das chapas de drywall nos EUA [1]. No Brasil a estimativa de descarte é de 5\% [3]. É possível reciclar gesso acartonado, produzindo aglomerantes, desde que sejam removidos contaminantes incorporados no processo de geração de resíduos $[1,4]$. De acordo com dados da Associação Brasileira do Drywall [5], quando o gesso é segregado dos demais resíduos da construção civil, é viável a reinserção do material nos seus processos de fabricação, já que o gesso volta a possuir as características químicas da sua matéria-prima, a gipsita. Entretanto, os resíduos devem estar completamente livres de quaisquer outras impurezas para que sua reutilização seja possível.

A reciclagem do gesso acartonado pode ser dividida em duas partes. Em primeiro lugar, o revestimento de papel é removido do núcleo de gesso. Em segundo lugar, o núcleo de gesso é triturado através de um picador mecânico até que o material apresente a granulometria desejada [6]. Isaia [2] relata que uma das primeiras empresas que utilizou gesso acartonado reciclado em sua produção é a British Plaster Board do Canadá, que afirma utilizar até $22 \%$ de gesso reciclado sem qualquer prejuízo no desempenho. $\mathrm{Na}$ Finlândia, uma das empresas do grupo Saint-Gobain, a 
Gyproc, utiliza de 10 a 25\% de gesso reciclado na fabricação dos seus produtos [7]. Cavalcanti [8] cita a empresa canadense New West Gypsum Recycling, que desde 1986 recicla placas de gesso acartonado. Esse processo foi desenvolvido na Dinamarca e desde 2001 é amplamente utilizado no país [9]. Alguns países da Escandinávia obtiveram taxa recorde mundial de até $80 \%$ de reciclagem de chapas drywall, tanto para construção novas ou resíduos de demolição [10]. A recuperação da capacidade aglomerante do gesso ocorre através do processo de calcinação. Através da calcinação, o resíduo de gesso que se apresenta como sulfato de cálcio di-hidratado $\left(\mathrm{CaSO}_{4} \cdot 2 \mathrm{H}_{2} \mathrm{O}\right)$ é convertido em gesso reciclado $\left(\mathrm{CaSO}_{4} \cdot 1,5 \mathrm{H}_{2} \mathrm{O}+0,5 \mathrm{H}_{2} \mathrm{O}\right)$. A calcinação é feita submetendo-se o resíduo de gesso a queima com temperaturas controladas [11].

Os gessos comerciais apresentam granulometria menor que os gessos reciclados, o que afeta a taxa de hidratação, que aumenta com a diminuição do tamanho das partículas, pois há aumento na área específica do material [12]. Para massa unitária, o limite mínimo determinado pela ABNT NBR 13207/94 [13] é de $700 \mathrm{~kg} / \mathrm{m}^{3}$. No entanto, a massa unitária do gesso reciclado é inferior à massa unitária do gesso comercial [14]. A quantidade de água, necessária para que a pasta de gesso adquira consistência adequada à sua utilização, depende da superfície específica, da finura, da forma e da distribuição dos grãos de gesso. Quanto maior a superfície específica, maior a área de reação, mais rápida a dissolução e menor o período de indução do material e, consequentemente, mais rápido é o início de pega do material [14]. A relação água/gesso é o parâmetro de maior influência na cinética da reação de hidratação e, consequentemente, na pega do gesso $[12,14,15]$. Quanto maior a quantidade de água de amassamento, maior o período de indução e retardamento no início da precipitação dos cristais de dihidrato, pois as distâncias entre as partículas aumentam com o aumento da relação água/gesso e, portanto, os cristais de di-hidrato têm mais espaço para crescer; assim, o tempo de pega aumenta, pois o crescimento dos cristais é mais lento [12].

As propriedades físicas e mecânicas do gesso, no estado endurecido, são influenciadas diretamente pela formação de sua microestrutura, em particular, pela porosidade e pela forma de entrelaçamento dos cristais [12]. A resistência à flexão é um indicador de resistência mecânica, representando a capacidade que um determinado corpo possui de resistir a esforços transversais. Os gessos nacionais apresentam resistência à tração na flexão que varia de 4,40 a $10,50 \mathrm{MPa}$, porém os reciclados apresentam valores de resistências à tração entre 0,7 e 3,5 $\mathrm{MPa}$ [11]. A resistência à compressão é outro indicador da resistência mecânica e representa a capacidade que um determinado corpo tem para resistir aos esforços de compressão axial [11]. As pastas de gesso endurecidas podem atingir resistências à compressão entre 5 e 15 MPa. Na NBR 13207/94 [13], são estabelecidos valores maiores do que $8,40 \mathrm{MPa}$ para a resistência à compressão do gesso. Desta forma, o objetivo deste trabalho é investigar as propriedades físicas e mecânicas da argamassa de gesso reciclado, no estado fresco e endurecido, utilizando resíduos gerados na execução de paredes e forros de gesso acartonado.

\section{MATERIAIS E MÉTODOS}

Para preparação do material para ensaio foram coletados $150 \mathrm{~kg}$ de resíduos de chapas de gesso acartonado descartados em obras de Curitiba em 20/04/2014. Em posse deste resíduo adotou-se a metodologia para produção do material na forma de pó. Os resíduos das chapas de gesso acartonado foram recortados em filetes de aproximadamente $3 \mathrm{~cm}$ pelo comprimento total do resíduo, com a utilização de estiletes retráteis para facilitar o processo de trituramento manual.

Trituramento manual e trituramento eletromecânico: foi utilizado um cilindro para massas manual Malta Mini Doro 2 com distância entre os cilindros ajustada para $10 \mathrm{~mm}$, realizando assim uma pressão sobre os filetes de chapas com espessura de 12,5 $\mathrm{mm}$, para separar o papel da massa de gesso. Após a separação, o cilindro foi ajustado para $3 \mathrm{~mm}$ e novamente prensada a massa de gesso para redução da dimensão das partículas. Os $150 \mathrm{~kg}$ de resíduos produziram 82 $\mathrm{kg}$ de massa de gesso prensada, sendo $68 \mathrm{~kg}$ correspondentes a papel e uma quantidade de material ainda aderida no cartão da chapa.

Em seguida utilizou-se o mesmo modelo de cilindro descrito acima, porém com modificação da instalação de um motor de tanquinho com potência de $240 \mathrm{~W}$ instalado com correias de borracha ligadas diretamente no eixo principal do cilindro, elevando a rotação para $350 \mathrm{rpm}$. Utilizou-se o espaçamento de $1 \mathrm{~mm}$ entre os cilindros. Colocou-se o material na cuba de contenção onde o material desceu por gravidade até os cilindros paulatinamente através de uma abertura no fundo da cuba, onde a própria vibração da máquina regeu a descida do material pela cuba até os cilindros (Fig. 1). O material caiu diretamente em sacos plásticos e foi armazenado para então ocorrer a repetição deste processo, isto é, a segunda passagem do material pelo cilindro eletromecânico. O material foi pesado e embalado em sacos plásticos com capacidade de $5 \mathrm{~kg}$.

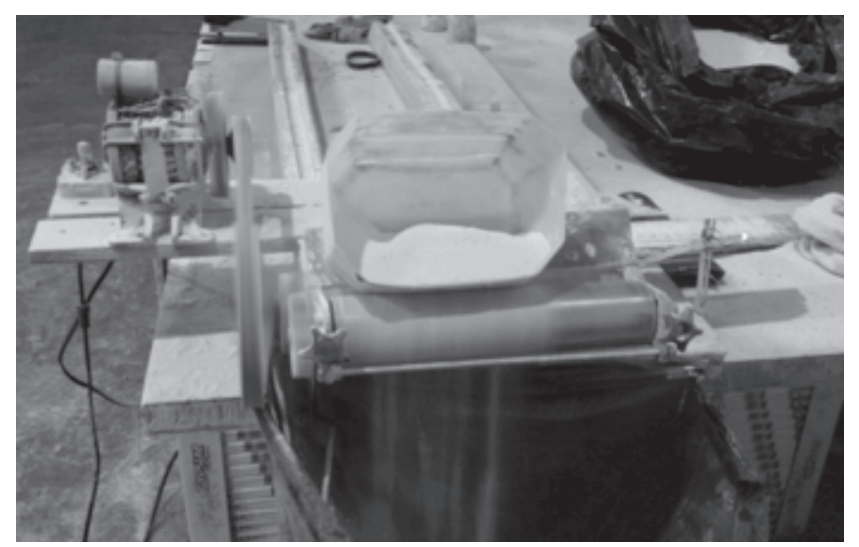

Figura 1: Trituramento eletromecânico para redução do tamanho das partículas.

[Figure 1: Electromechanical crushing to reduce particle size.] 
Calcinação do resíduo de gesso: o conteúdo de cada embalagem com $5 \mathrm{~kg}$ de material foi colocado na fôrma de alumínio e inserido na estufa elétrica de esterilização e secagem com renovação e circulação de ar forçado com termostato digital Biopar para execução do processo de calcinação. Cada amostra de aproximadamente $5 \mathrm{~kg}$ foi calcinada nas temperaturas de 160,180 e $200{ }^{\circ} \mathrm{C}$, para verificação de uma possível diferença entre os parâmetros analisados. Tais amostras permaneceram na estufa por 1 , 2, 4, 8 e 24 h; após este período, o gesso foi colocado em repouso por $10 \mathrm{~min}$, armazenado em sacolas plásticas e identificado.

Granulometria: foi realizado segundo as prescrições da NBR 12.127/91 [16], onde o material seco em estufa foi submetido ao peneiramento mecânico sequencial, em peneiras normatizadas com aberturas de malha de 1,18 , $0,59,0,42,0,297,0,149$ e $0,075 \mathrm{~mm}$. Foram realizadas 3 amostragens, onde uma massa de $100 \mathrm{~g}$ foi depositada no conjunto de peneiras com o fundo. Após colocar a tampa, o conjunto foi inserido sobre um agitador de peneiras eletromagnético por $10 \mathrm{~min}$. Após este período, o material de cada peneira foi pesado em uma balança digital Digimed KN 5000 com precisão de $0,1 \mathrm{~g}$ para realização da média aritmética do percentual retido nas peneiras.

Massa unitária e módulo de finura: foram realizados em conformidade com as prescrições da NBR 12.127/91 [16], onde o material seco em estufa foi depositado em um recipiente $(15,1 \mathrm{~cm} \times 15,1 \mathrm{~cm} \times 15,1 \mathrm{~cm})$ de volume $\left(3442,95 \mathrm{~cm}^{3}\right)$ e massa $(13770 \mathrm{~g})$ conhecidos até seu transbordamento e nivelamento final. Foram realizadas 5 amostragens para cada temperatura.

Preparação da pasta: a pasta de gesso reciclado foi preparada através da mistura homogênea de gesso reciclado e água, utilizando a relação água / gesso (a/g) de 0,7 , em massa, valor característico utilizado em obras [12]. Para preparação da pasta foi utilizado o procedimento previsto na NBR 12128/91 [17], onde o pó de gesso foi polvilhado sobre a água por um período de tempo de 1 min. A suspensão foi deixada em repouso por mais $1 \mathrm{~min}$ e então foi homogeneizada manualmente com a utilização de uma espátula por 1 min para obtenção de uma pasta isenta de grumos.

Tempos de inicio e fim de pega: foram determinados segundo a norma NBR 12128/91 [17]. Para determinação do tempo de pega foi utilizado o aparelho de Vicat, onde a agulha do aparelho penetrou na pasta sobre a ação da gravidade. $\mathrm{O}$ início de pega foi cronometrado a partir do momento em que o gesso reciclado entrou em contato com a água e onde a agulha do aparelho estacionou a $1 \mathrm{~mm}$ da base. O fim de pega foi apontado a partir do momento em que a agulha não deixava mais impressão sobre a pasta de gesso reciclado. Foram realizadas 3 medições para cada temperatura e para cada tempo de permanência na estufa.

Moldagem dos corpos de prova: foram utilizados moldes metálicos padronizados, onde foi possível moldar 3 corpos de prova de $4 \mathrm{~cm} \times 4 \mathrm{~cm} \times 16 \mathrm{~cm}$. Os moldes foram posicionados sobre a bancada e untados com cera líquida para facilitar a remoção posterior dos corpos de prova. Os moldes foram preenchidos com pasta de gesso reciclado, em 3 camadas, pressionando a pasta sobre as paredes do molde para evitar o aprisionamento de ar. Foram moldados 15 corpos de prova para cada temperatura e para cada tempo em permanência em estufa, sendo 5 para os ensaios de 3 dias, 5 para 7 dias e 5 para 28 dias. Decorridas $2 \mathrm{~h}$ após a moldagem, os moldes foram desmontados e os corpos de prova identificados e armazenados em local seco a temperatura ambiente.

Resistência à tração na flexão: foi determinada utilizando os corpos de prova seguindo as recomendações da NBR12142/91 [18]. Cinco corpos de prova de cada temperatura e de cada tempo em permanência em estufa foram colocados em máquina universal de ensaios, eletromecânica e microprocessada EMIC DL100T, e rompidos com utilização de um dispositivo para ensaios de flexão em corpos de prova prismáticos Solotest, específico para o ensaio.

Resistência à compressão: foi determinada pelo ensaio descrito na norma NBR 12129/91 [19], onde 5 corpos de prova de cada temperatura e de cada tempo em permanência em estufa resultantes da sobra rompida no ensaio de tração na flexão foram submetidas ao ensaio de compressão. $\mathrm{O}$ corpo de prova foi posicionado na máquina de ensaios mecânicos entre duas placas de metal transversais aos corpos de prova, atribuindo assim uma seção de ruptura com dimensões de $4 \mathrm{~cm} \times 4 \mathrm{~cm}$ em cada face.

\section{RESULTADOS E DISCUSSÃO}

\section{Granulometria}

A granulometria foi determinada em laboratório e os valores calculados para os gessos reciclados calcinados em estufa às temperaturas de 160,180 e $200^{\circ} \mathrm{C}$ são mostrados na Fig. 2. Foi possível verificar que a granulometria entre as amostras é similar, não ocorrendo grande variação em função da temperatura.

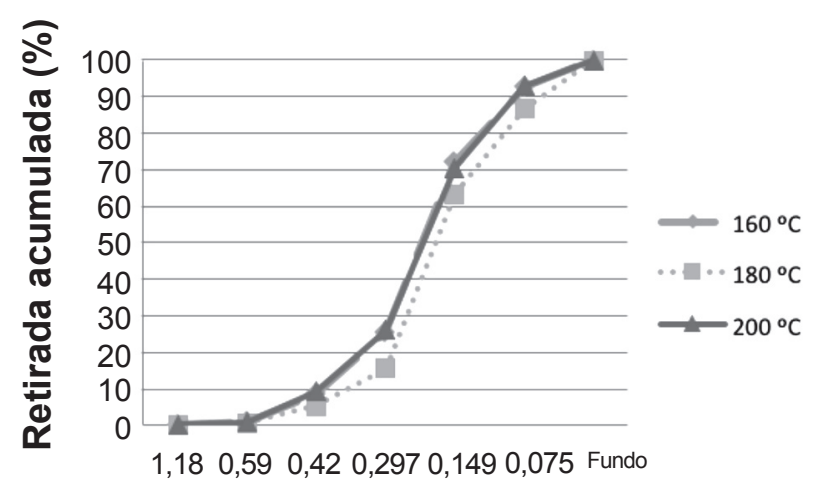

\section{Abertura das peneiras $(\mathrm{mm})$}

Figura 2: Curvas granulométricas dos gessos reciclados.

[Figure 2: Particle size distribution curves of the recycled gypsums.] 


\section{Determinação da massa unitária e módulo de finura}

Os valores da massa unitária e do módulo de finura são apresentados nas Tabelas I e II, respectivamente. Pôdese mensurar a massa unitária para os gessos reciclados calcinados em estufa a 160,180 e $200{ }^{\circ} \mathrm{C}$, sendo estes 528,73 $\mathrm{kg} / \mathrm{m}^{3}, 531,23 \mathrm{~kg} / \mathrm{m}^{3}$ e $529,78 \mathrm{~kg} / \mathrm{m}^{3}$, respectivamente. $\mathrm{Na}$ literatura [11] é possível encontrar valores de $549,57 \mathrm{~kg} / \mathrm{m}^{3}$ para calcinação a $180{ }^{\circ} \mathrm{C}$ e $531,40 \mathrm{~kg} / \mathrm{m}^{3}$ para calcinação a $200{ }^{\circ} \mathrm{C}$, ou seja, valores próximos dos encontrados no ensaio. Nenhum dos valores obtidos atende o requisito da massa unitária da NBR 13207/94 [13] cuja exigência é de $700 \mathrm{~kg} / \mathrm{m}^{3}$. É possível afirmar que a massa unitária não varia em função da temperatura, pois a diferença de valor entre elas não ultrapassa $0,5 \%$. Supõe-se que seria possível obter a massa unitária sugerida pela NBR 13207/94 [13] caso fosse utilizado outro mecanismo para redução do tamanho das partículas, como um moinho de cilindros industrial.

De acordo com a NBR 13207/94 [13] um dos critérios para classificação do gesso leva em conta o módulo de finura. Os valores obtidos foram inferiores a 1,10; logo, o gesso reciclado pode ser classificado como gesso fino para revestimento ou como gesso fino para fundição, para uma classificação mais detalhada é necessário determinar o tempo de pega, descrito no próximo item. $\mathrm{O}$ módulo de finura obtido foi similar ao encontrado na literatura [12] com gesso reciclado, obtendo o valor de 1,17 para calcinação a $180^{\circ} \mathrm{C}$ e 0,92 para calcinação a $200{ }^{\circ} \mathrm{C}$. É possível verificar que o módulo de finura do gesso reciclado a $180{ }^{\circ} \mathrm{C}$ é maior somente analisando o gráfico de granulometria (Fig. 2), pois este apresenta um leve deslocamento na curva à direita, demonstrando que a dimensão das partículas é menor.

\section{Tempo de pega}

Para determinação da propriedade no estado fresco foi realizado o ensaio de início e fim de pega. Os valores aferidos estão dispostos na Tabela III e apresentados

Tabela I - Determinação da massa unitária do gesso reciclado.

[Table I - Determination of bulk density of the recycled gypsum.]

\begin{tabular}{cccc}
\hline Temperatura $\left({ }^{\circ} \mathrm{C}\right)$ & 160 & 180 & 200 \\
\hline Massa do recipiente cheio $(\mathrm{g})$ & 15590,4 & 15559 & 15594 \\
Massa do recipiente vazio $(\mathrm{g})$ & 13770 & 13770 & 13770 \\
Massa de gesso $(\mathrm{g})$ & $1820,4 \pm 9,24$ & $1829 \pm 18,51$ & $1824 \pm 15,57$ \\
Massa unitária $\left(\mathrm{kg} / \mathrm{m}^{3}\right)$ & 528,73 & 531,23 & 529,78 \\
\hline
\end{tabular}

Tabela II - Determinação do módulo de finura do gesso reciclado. [Table II - Determination of fineness modulus of the recycled gypsum.]

\begin{tabular}{cccc}
\hline Temperatura $\left({ }^{\circ} \mathrm{C}\right)$ & 160 & 180 & 200 \\
\hline$\sum \%$ retida acumulada na peneira $0,59 \mathrm{~mm}$ & 0,8 & 0,6 & 0,83 \\
$\sum \%$ retida acumulada na peneira $0,42 \mathrm{~mm}$ & 8,4 & 5,37 & 9,3 \\
$\sum \%$ retida acumulada na peneira $0,297 \mathrm{~mm}$ & 25,23 & 15,63 & 26,13 \\
$\sum \%$ retida acumulada na peneira $0,149 \mathrm{~mm}$ & 72,13 & 63,27 & 70,57 \\
$\sum \%$ retida acumulada total & 106,57 & 84,87 & 106,83 \\
Módulo de finura & 1,07 & 0,85 & 1,07 \\
\hline
\end{tabular}

Tabela III - Tempos de início e fim de pega dos gessos reciclados calcinados a 160,180 e $200{ }^{\circ} \mathrm{C}$.

[Table III - Start and end times of setting of recycled plasters calcined at 160,180 and $200^{\circ} \mathrm{C}$.]

\begin{tabular}{ccc}
\hline Pastas & $\begin{array}{c}\text { Início de pega } \\
\text { (h:min:s) }\end{array}$ & $\begin{array}{c}\text { Fim de pega } \\
\text { (h:min:s) }\end{array}$ \\
\hline $160^{\circ} \mathrm{C}-4 \mathrm{~h}$ & $00: 06: 00$ & $00: 08: 45$ \\
$160^{\circ} \mathrm{C}-24 \mathrm{~h}$ & $00: 33: 59$ & $00: 54: 39$ \\
$180{ }^{\circ} \mathrm{C}-4 \mathrm{~h}$ & $00: 47: 24$ & $01: 38: 31$ \\
$180{ }^{\circ} \mathrm{C}-24 \mathrm{~h}$ & $00: 26: 34$ & $00: 55: 50$ \\
$200{ }^{\circ} \mathrm{C}-4 \mathrm{~h}$ & $00: 09: 31$ & $00: 14: 36$ \\
$200{ }^{\circ} \mathrm{C}-24 \mathrm{~h}$ & $00: 05: 09$ & $00: 08: 08$ \\
\hline
\end{tabular}

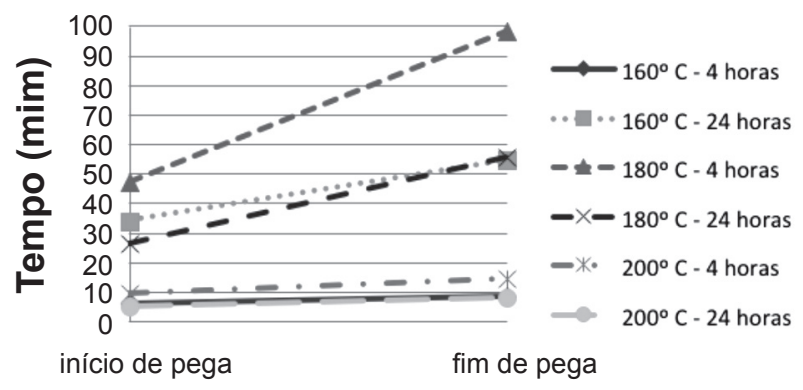

Figura 3: Tempos de início e fim de pega dos gessos reciclados. [Figure 3: Start and end times of setting of the recycled gypsums.] 
graficamente na Fig. 3. Comparando os valores obtidos com o estipulado pela NBR 13207/94 [13], pode-se afirmar que os gessos a $160{ }^{\circ} \mathrm{C}-24 \mathrm{~h}, 180{ }^{\circ} \mathrm{C}-4 \mathrm{~h}$ e $180^{\circ} \mathrm{C}-24$ $\mathrm{h}$ atendem às exigências quanto ao quesito tempo de pega e módulo de finura, atingindo a classificação como gesso fino para revestimento. As pastas a $160{ }^{\circ} \mathrm{C}-1 \mathrm{~h}, 180^{\circ} \mathrm{C}-1$ $\mathrm{h}$ e $200{ }^{\circ} \mathrm{C}-1 \mathrm{~h}$ apresentaram endurecimento instantâneo após inserção na água, com formação de grumos que não puderam ser homogeneizados, apresentando um falso início de pega, e não apresentaram fim de pega em $72 \mathrm{~h}$. As pastas a $160{ }^{\circ} \mathrm{C}-2 \mathrm{~h}, 180{ }^{\circ} \mathrm{C}-2 \mathrm{~h}$ e $200{ }^{\circ} \mathrm{C}-2 \mathrm{~h}$ não puderam ser homogeneizadas com a relação a/g 0,7 , sendo que apresentaram caráter muito seco após polvilhamento sobre a água. As pastas a $160{ }^{\circ} \mathrm{C}-8 \mathrm{~h}, 180{ }^{\circ} \mathrm{C}-8 \mathrm{~h}$ e $200{ }^{\circ} \mathrm{C}-8$ $\mathrm{h}$ proporcionaram misturas muito homogêneas, apresentado um estado quase liquefeito, porém estas amostras não apresentaram início, tampouco fim de pega.

\section{Determinação da resistência à tração na flexão}

Foram moldados corpos de prova apenas com as amostras de gesso reciclado $160{ }^{\circ} \mathrm{C}-4 \mathrm{~h}, 160^{\circ} \mathrm{C}-24 \mathrm{~h}, 180{ }^{\circ} \mathrm{C}-4$ h, $180{ }^{\circ} \mathrm{C}-24 \mathrm{~h}, 200{ }^{\circ} \mathrm{C}-4 \mathrm{~h}$ e $200{ }^{\circ} \mathrm{C}-24 \mathrm{~h}$. Os corpos moldados ficaram em repouso por 3, 7 e 28 dias e após estes períodos foram feitos o rompimento dos corpos de prova na máquina de ensaios com dispositivo para ensaio de flexão; os resultados obtidos estão dispostos na Tabela IV e na Fig. 4.

Tabela IV - Valores obtidos no ensaio de resistência à tração na flexão (MPa).

[Table IV - Values obtained in the flexural tensile strength test $(M P a)$.]

\begin{tabular}{cccc}
\hline Amostras & 3 dias & 7 dias & 28 dias \\
\hline $160^{\circ} \mathrm{C}-4 \mathrm{~h}$ & $0,62 \pm 0,10$ & $0,78 \pm 0,04$ & $1,14 \pm 0,35$ \\
$160^{\circ} \mathrm{C}-24 \mathrm{~h}$ & $1,52 \pm 0,07$ & $1,37 \pm 0,11$ & $1,57 \pm 0,16$ \\
$180^{\circ} \mathrm{C}-4 \mathrm{~h}$ & - & $0,44 \pm 0,01$ & $0,29 \pm 0,06$ \\
$180^{\circ} \mathrm{C}-24 \mathrm{~h}$ & $1,66 \pm 0,08$ & $1,53 \pm 0,06$ & $1,85 \pm 0,29$ \\
$200^{\circ} \mathrm{C}-4 \mathrm{~h}$ & $0,89 \pm 0,11$ & $1,82 \pm 0,24$ & $1,90 \pm 0,10$ \\
$200^{\circ} \mathrm{C}-24 \mathrm{~h}$ & $1,72 \pm 0,06$ & $1,05 \pm 0,08$ & $0,96 \pm 0,19$ \\
\hline
\end{tabular}

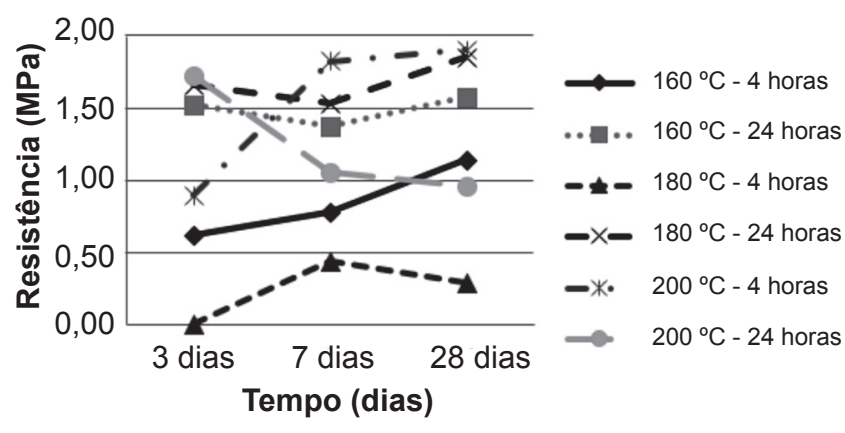

Figura 4: Resistência à tração na flexão dos gessos reciclados. [Figure 4: Flexural strength of recycled gypsum].
Tabela V - Resistência à compressão dos gessos reciclados (MPa).

[Table $V$ - Compressive strength of the recycled gypsums (MPa).]

\begin{tabular}{cccc}
\hline Amostras & 3 dias & 7 dias & 28 dias \\
\hline $160{ }^{\circ} \mathrm{C}-4 \mathrm{~h}$ & $1,39 \pm 0,24$ & $2,01 \pm 0,29$ & $4,46 \pm 1,02$ \\
$160{ }^{\circ} \mathrm{C}-24 \mathrm{~h}$ & $4,61 \pm 0,38$ & $4,55 \pm 0,49$ & $4,54 \pm 0,37$ \\
$180{ }^{\circ} \mathrm{C}-4 \mathrm{~h}$ & - & $1,24 \pm 0,03$ & $0,76 \pm 0,14$ \\
$180^{\circ} \mathrm{C}-24 \mathrm{~h}$ & $5,53 \pm 0,16$ & $4,49 \pm 0,52$ & $6,05 \pm 2,12$ \\
$200{ }^{\circ} \mathrm{C}-4 \mathrm{~h}$ & - & $5,23 \pm 0,31$ & $4,28 \pm 0,75$ \\
$200{ }^{\circ} \mathrm{C}-24 \mathrm{~h}$ & $4,42 \pm 1,20$ & $2,90 \pm 0,24$ & $1,78 \pm 0,19$ \\
\hline
\end{tabular}

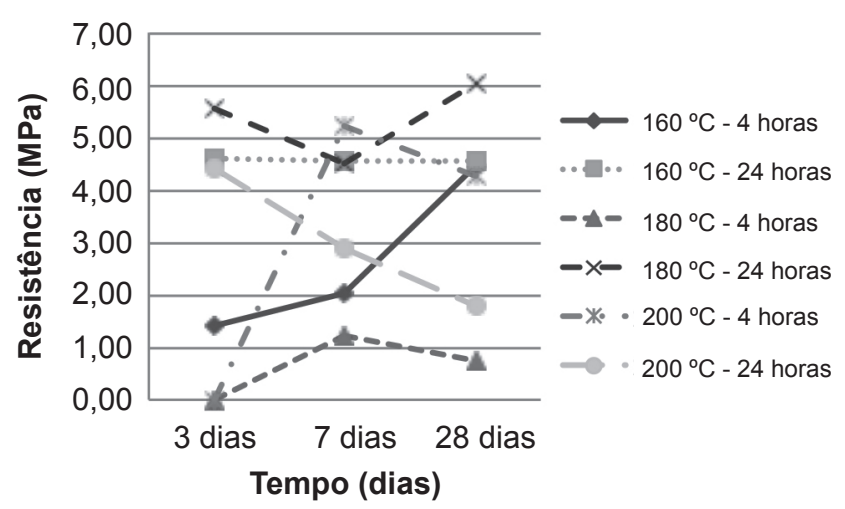

Figura 5: Resistência à compressão dos gessos reciclados. [Figure 5: Compressive strength of the recycled gypsums.]

As amostras de gesso reciclado obtiveram resultados dentro do intervalo sugerido por Savi [11], isto é, entre 0,7 e $3,5 \mathrm{MPa}$, com exceção da amostra $180^{\circ} \mathrm{C}-4 \mathrm{~h}$ e a amostra $160{ }^{\circ} \mathrm{C}-4 \mathrm{~h}-3$ dias. Das amostras ensaiadas, nota-se que os maiores valores alcançados foram as amostras de $160^{\circ} \mathrm{C}$ - $24 \mathrm{~h}, 180{ }^{\circ} \mathrm{C}-24 \mathrm{~h}$ e $200{ }^{\circ} \mathrm{C}-4 \mathrm{~h}$. Algumas amostras tiveram decréscimo em seu valor de resistência à tração na flexão para 7 e 28 dias, em relação à resistência para 3 dias, ou seja, não necessariamente o valor de resistência à tração na flexão aumenta com o passar dos dias, como observado nas amostras $180{ }^{\circ} \mathrm{C}-4 \mathrm{~h}$ e $200{ }^{\circ} \mathrm{C}-24 \mathrm{~h}$, onde o valor foi decrescendo ao longo do tempo. A amostra $180{ }^{\circ} \mathrm{C}-4$ h - 3 dias não pode ser ensaiada pois os corpos de prova desmancharam antes mesmo de sua colocação na máquina de ensaios mecânicos, isto é, a pasta não estava homogênea e formou um corpo de prova frágil.

\section{Determinação da resistência à compressão}

Os corpos de prova foram rompidos em compressão na máquina de ensaios mecânicos; os valores de resistência à compressão obtidos estão representados na Tabela V e na Fig. 5.

A amostra $180^{\circ} \mathrm{C}-24 \mathrm{~h} \mathrm{e} 200^{\circ} \mathrm{C}-4 \mathrm{~h}$ foram as amostras que atingiram o valor sugerido [11], acima de $5 \mathrm{MPa}$. Em nenhuma das amostras foi verificada a exigência mínima de 8,40 MPa descrito pela NBR 13207/94 [13]. Assim como no ensaio de resistência à tração na flexão, as amostras que 
alcançaram maiores valores foram as amostras $160^{\circ} \mathrm{C}-4 \mathrm{~h}$, $160{ }^{\circ} \mathrm{C}-24 \mathrm{~h}, 180^{\circ} \mathrm{C}-24 \mathrm{~h}$ e $200{ }^{\circ} \mathrm{C}-4 \mathrm{~h}$. Na maioria das amostras foi verificado acréscimo no valor da resistência à compressão, com exceção das amostras $180{ }^{\circ} \mathrm{C}-4$ h e 200 ${ }^{\circ} \mathrm{C}-24 \mathrm{~h}$, que apresentaram redução neste valor. As amostras $180{ }^{\circ} \mathrm{C}-4 \mathrm{~h}-3$ dias e $200{ }^{\circ} \mathrm{C}-4 \mathrm{~h}-3$ dias não puderam ser ensaiadas, pois os corpos de prova desmanchavam antes mesmo de sua colocação na prensa, isto é, a pasta não estava homogênea, formando corpos de prova frágeis

\section{CONCLUSÕES}

Este trabalho serve de ponto de partida para uma série de estudos sobre a reciclagem do gesso contido nas chapas de gesso acartonado. A metodologia utilizada em laboratório foi eficiente, pois após a reidratação foi possível moldar corpos de prova sólidos somente utilizando resíduo de gesso.

Foi possível verificar que a granulometria entre as amostras é similar, não ocorrendo grande variação em função da temperatura de calcinação. A massa unitária não atingiu o valor mínimo estipulado pela NBR 13207/94, porém os valores foram similares aos descritos na literatura. As três temperaturas de calcinação analisadas resultaram em amostras que formaram corpos de prova sólidos somente com utilização do gesso reciclado. Dentre os tempos de permanência em estufa e as temperaturas analisadas, pode-se dizer que as amostras de 1,2 e $8 \mathrm{~h}$, submetidas às temperaturas de 160,180 e $200{ }^{\circ} \mathrm{C}$, não são recicláveis, pois não apresentaram fim de pega em $72 \mathrm{~h}$.

Nenhum dos corpos de prova moldados somente com gesso reciclado atende aos requisitos mínimos estipulados na NBR 13207/94 de resistência à compressão e dureza superficial. Mesmo assim, sugere-se a aplicação direta na confecção de estátuas e imagens, pois tais artefatos não demandam de uma resistência elevada. Nenhuma das amostras atendeu aos quesitos da NBR 13207/94 simultaneamente, logo o gesso reciclado não pode ser classificado como gesso comercial. Demonstra-se assim que o resíduo hoje descartado pode vir a ser reutilizado gerando não só novos nichos de mercado, como também colocar este produto hoje nocivo ao meio ambiente na esfera sustentável.

\section{REFERÊNCIAS}

[1] Placo do Brasil, Mercado de drywall segue em expansão, S. Paulo, Brasil (2014).

[2] G.C. Isaia, Materiais de construção civil e princípios de ciência e engenharia de materiais, $2^{\mathrm{a}}$ Ed., Ibracon, S. Paulo, Brasil (2007) 727.

[3] Siniat, "Drywall - perguntas frequentes", Rio de Janeiro,
Brasil (2014).

[4] E. Marvin, "Gypsum wallboard recycling and reuse opportunities in the state of Vermont", Waste Management Division Vermont Agency of Natural Resources, Vermont, Estados Unidos (2000) 44.

[5] Associação Brasileira do Drywall, "Mercado do drywall no Brasil", S. Paulo, Brasil (2012).

[6] C. Bauer, "Gypsum Recycling in PlaNYC 2030: Spaces for Government Intervention", Systemic Action Research in the Built Environment 3 (2011) 14.

[7] Gyproc Saint-Gobain Group, "Gypsum Environmental”, Kyrkslätt, Finlândia (2014).

[8] L.B. Cavalcanti, "Determinação de condições operacionais adequadas na desidratação do minério de gipsita para obtenção de um gesso beta reciclável”, Diss. Mestrado em Engenharia Civil, Universidade Católica de Pernambuco, Recife, PE, Brasil (2006).

[9] Portal Resíduos Sólidos, Reciclagem do Gesso, Belém, PA, Brasil (2013).

[10] "New West Gypsum Recycling, Recovery process", Avonmouth, United Kingdom (2014).

[11] O. Savi, "Produção de placas de forro com a reciclagem do gesso", IX Enc. Tecnol. Eng. Civil e Arquit., Maringá, PR (2013).

[12] P.S. Bardella, "Recycled Plaster: Physical and Mechanical Properties", Int. Conf. Technol. Archit. Structure, Xian 1 (2011) 1307.

[13] Associação Brasileira de Normas Técnicas, NBR 13207, "Gesso para construção civil - Especificação," Rio de Janeiro, RJ (1994).

[14] S.M. de M. Pinheiro, "Gesso reciclado: avaliação de propriedades para uso em componentes", Tese Dr., Universidade Estadual de Campinas, Campinas, SP (2011).

[15] A.S. Ribeiro, "Produção de gesso reciclado a partir de resíduos oriundos da construção civil", Diss. Mestrado em Engenharia Urbana, Universidade Federal da Paraíba, J. Pessoa, PB (2006).

[16] Associação Brasileira de Normas Técnicas, NBR 12127, "Gesso para construção: determinação das características físicas do pó”, Rio de Janeiro, RJ (1991).

[17] Associação Brasileira de Normas Técnicas, NBR 12128, "Gesso para construção: determinação das propriedades físicas da pasta", Rio de Janeiro, RJ (1991).

[18] Associação Brasileira de Normas Técnicas, NBR 12142, "Determinação da resistência à tração na flexão de corpos de prova prismáticos", Rio de Janeiro, RJ (1991).

[19] Associação Brasileira de Normas Técnicas, NBR 12129, "Gesso para construção: determinação das propriedades", Rio de Janeiro, RJ (1991).

(Rec. 04/05/2015, Rev. 21/06/2015, 20/09/2015, Ac. $22 / 09 / 2015)$ 